\title{
Personalized medicine in severe influenza
}

\author{
F. Valenzuela-Sánchez ${ }^{1}$ B. Valenzuela-Méndez ${ }^{2,3} \cdot$ J. F. Rodríguez-Gutiérrez ${ }^{4}$. \\ J. Rello ${ }^{5,6}$
}

Received: 11 February 2016 / Accepted: 11 February 2016/Published online: 2 March 2016

(C) Springer-Verlag Berlin Heidelberg 2016

\begin{abstract}
Existing therapies against infectious diseases may only be effective in limited subpopulations during specific phases of diseases, incorporating theranostics, and there is a clear need to individualize different therapeutic approaches depending on the host. Influenza A virus infection evolves into a severe respiratory failure in some young adult patients, related to an exaggerated inflammatory response. Mortality rates remain high despite antiviral treatment and aggressive respiratory support. The influenza A virus (IAV) infection will induce a proinflammatory innate immune response through recognition of viral RNA by Toll-like receptor (TLR) 7 and retinoic acid-inducible gene 1 (RIG-I) molecules by nuclear
\end{abstract}

J. Rello

JRello@crips.es

F. Valenzuela-Sánchez

pacovae@yahoo.es

B. Valenzuela-Méndez

blavalmen@gmail.com

J. F. Rodríguez-Gutiérrez

kikorg1977@hotmail.com

1 Critical Care Medicine Department, University Hospital SAS of Jerez, Jerez de la Frontera, Spain

2 Gynecology and Obstetrics Department, University Hospital Germans Trias i Pujol, Barcelona, Spain

3 Department of Medicine, Universitat Autònoma de Barcelona, Barcelona, Spain

4 Hematology Department, University Hospital SAS of Jerez, Jerez de la Frontera, Spain

5 CIBERES, Barcelona, Spain

6 Vall d'Hebron Institut de Recerca (VHIR), Universitat Autònoma de Barcelona, Barcelona, Spain factor kappa-light-chain-enhancer of activated B cells (NF- $\mathrm{kB}$ route). Anti-inflammatory therapies focused on modulating this inflammatory response to "all patients" have not been satisfactory. Steroids should be avoided because they do not improve survival and promote superinfections. Since clinical judgment has often been proven inadequate, interest in the use of biomarkers to monitor host response and to assess severity and complications is growing. It is well known that, if used appropriately, these can be helpful tools to predict not only severity but also mortality. We need more biomarkers that predict host response: it is time to change lactate measurement to proteomics and transcriptomics. Theranostics describes an approach covering both diagnosis and coupled therapy. Death is usually a fatal complication of a dysregulated immune response more than the acute virulence of the infectious agent. Future research demonstrating the usefulness of adjunctive therapy in a subset of critically ill patients with IAV pneumonia is an unmet clinical need.

\section{Introduction}

Young adults that were more vulnerable to infection and mortality had an inverted U-shape in the 1918 influenza pandemic [1]. This was re-observed in the 2009 pandemic [2]. Years later, influenza A virus (IAV) infection remained an important cause of intensive care unit (ICU) admission. Existing therapies are likely to be effective only in limited subpopulations during specific phases of diseases. The concept of "precision medicine" in prevention and treatment strategies that take individual variability into account has been used to guide blood transfusions for more than a century. The prospect to apply this concept more broadly has been improved by the recent development of large-scale biological databases (such as the Human Genome Project), powerful methods for 
characterizing patients (proteomics, metabolomics, transcriptomics, etc.), and computational tools to interrogate large datasets. Interaction between influenza and the host defines outcomes, whereas identification of subsets with influenza has recently been documented [3] (Fig. 1).

\section{The role of immunity and the host response}

The host perspective covers genetics, transcriptomics, and metabolomics, with implications for diagnosis and treatment. An individual history of immune-compromise, treatment with immune-suppressive drugs, hematologic diseases, or acquired immune deficiency syndrome (AIDS) is not related to the incidence and poor prognosis of IAV pneumonia [4, 5]. Transcription profiling of individual neutrophils via singlecell mRNA sequencing has been reported, with higher expression of inflammatory genes in non-survivors with shock. Antigen presentation in tRNA charging can explain prolonged viral shedding, influencing interferon signaling. Innate immune responsiveness is known to be different in different subjects. The IAV will induce a proinflammatory innate immune response through the recognition of viral RNA by toll- like receptor 7 (TLR7) and retinoic acid-inducible gene 1 (RIG-I) molecules, that induce the production of proinflammatory cytokines mediated nuclear factor kappa-light-chainenhancer of activated B cells (NF-KB route) and activate the antiviral response. Virus-infected lung cells elicit alveolar macrophage migration by chemokine ligand 2 and receptor (CCL2-CCR2) interaction and induce apoptosis of this infected cells. CD200 receptor (CD200R) in macrophages interacts with CD200 expressed on alveolar epithelium and downregulates the inflammatory response, including inhibition of IL- 6 and TNF $\alpha$ expression by macrophages. TCD 8 cells, stimulated by IL- 2 produced by TCD4 and IL27 released by macrophages, control the inflammatory response through IL10 production $[6,7]$.

Multiple studies described obesity and pregnancy as highrisk factors for IAV infection [8, 9]. Besides respiratory disorders, obese patients may have immunological alterations. Adiponectin, which reduces the activity of macrophages, is produced in smaller quantities in obese individuals [10]. Thus, the inflammatory response in an obese person infected by IAV may be amplified through high levels of proinflammatory cytokines. Pregnant women $[7,8]$ also have low levels of adiponectin.

\section{a BIOMARKERS OF SEVERITY}

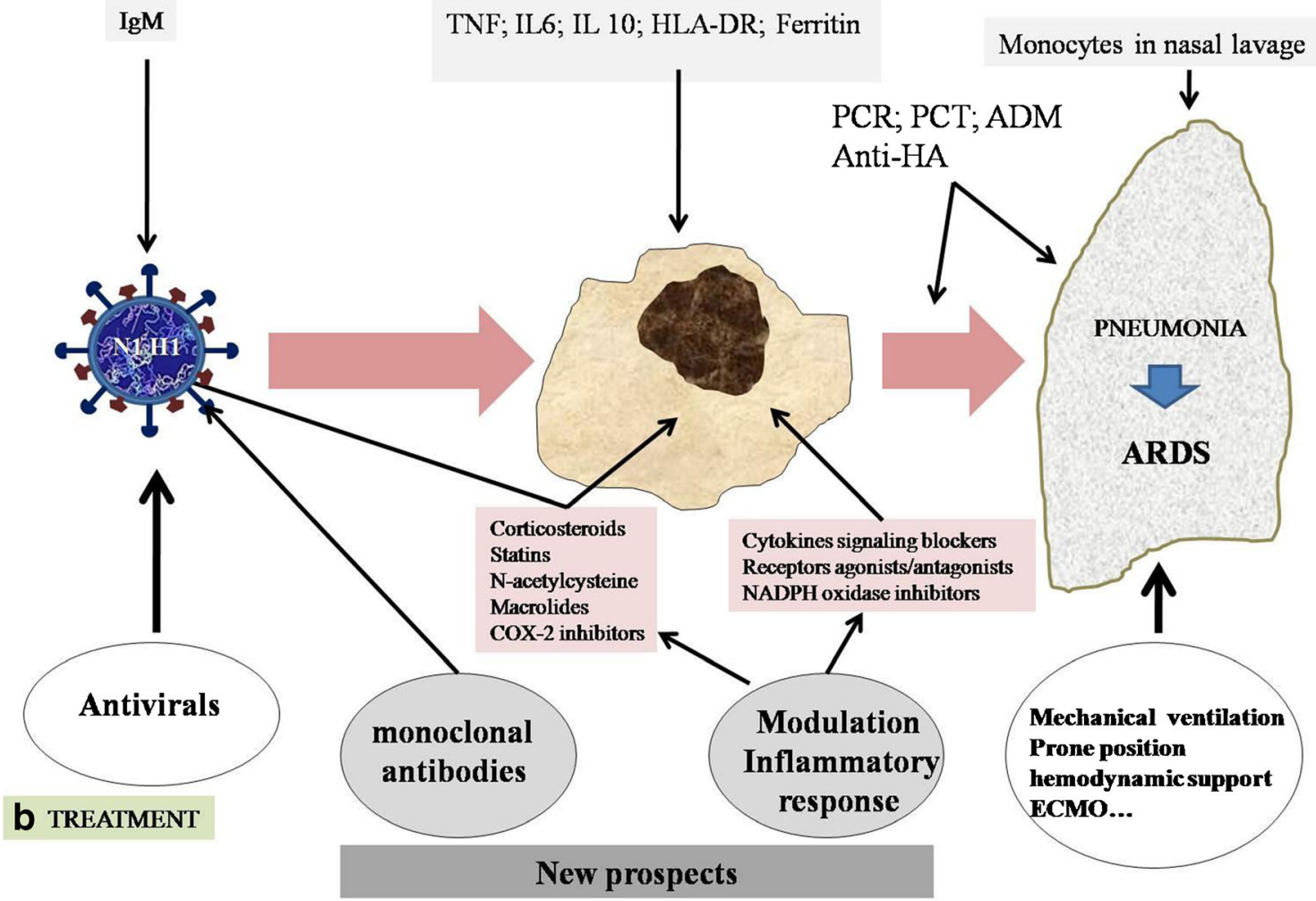

Fig. 1 Sequence of inflammatory activation due to influenza A virus (IAV) infection and its evolution into pneumonia and/or acute respiratory distress syndrome (ARDS). a Possibilities of finding biomarkers of severity in IAV infection. b Conventional treatment with antivirals and respiratory and hemodynamic support. Possibilities of new perspectives of treatment modulating the inflammatory response, generally or specifically, or the administration of monoclonal antibodies 


\section{Pulmonary bacterial coinfection/superinfection}

There is a proven relationship between influenza virus and bacterial infections, e.g., those caused by the pneumococcus, which is codetermined by immune factors, age, and comorbidities and bacterial sero- or genotype. During even low-level influenza epidemics, all hospitalized patients with pneumococcal pneumonia need additional and urgent influenza diagnostics [11]. Early IAV infection reduces susceptibility to superinfection by the creation of an environment rich in IL13, which does not inhibit the production of interferon- $\gamma$ (IFN $\gamma)$. Thus, phagocytosis and bacterial clearance is favored. Progression of IAV infection results in an increased susceptibility to secondary infection [12], also including Staphylococcus aureus, Haemophilus influenzae, and Aspergillus spp. Type I IFN, produced in response to IAV infection, results in an inhibition of synthesis of IL1B and IL23, and IL17 and IL22 release, reducing the production of antimicrobial peptides. It also reduces the level of neutrophil chemoattractants, such as chemokine (C-X-C motif) ligand 1 and 2 (CXCL1 and CXCL2), and can induce neutrophil extracellular traps (NETs) and IFN $\gamma$ and IL10 production [13].

\section{Biomarkers of severe respiratory organ failure}

Since clinical judgment has often been proven inadequate to define infection severity, interest in the use of biomarkers is growing. It is well known that, if used appropriately, they can be a helpful tool to predict both severity and mortality. Respiratory failure decides the course of the disease and non-specific factors, such as mechanical ventilation and APACHE II and SOFA scores, were related to poor prognosis [14]. The development of a specific host (or pathogen) marker for severity in IAV infection obtained quickly would be a substantial benefit.

The TRIAGE Study [15] has recently shown that the combination of mid-regional pro-adrenomedullin (MRproADM) and clinical information defines more significantly the power of severity stratification and the need for ICU admission. In community-acquired pneumonia, MR-proADM was a good biomarker for predicting short-term mortality assessed by a systematic review and meta-analysis [16]. Although the utility of this biomarker in IAV pneumonia has not been previously studied, recently, at the LIVES 2015 Congress, we reported that MR-proADM plasma levels as measured in the emergency department (ED) in adults with IAV pneumonia, without bacterial coinfection, was an effective tool to anticipate the risk of mortality and need for mechanical ventilation, being even more useful than procalcitonin (PCT) or C-reactive protein (CRP).
Similarly, HLA-DR expression in monocytes and ferritin levels in the ED identifies unfavorable evolution and elevated risk of mortality in patients with IAV pneumonia $[17,18]$. PCT measurement potentially assists in the discrimination between severe lower respiratory tract infections of bacterial and IAV origin. In patients admitted to the ICU with IAV pneumonia, PCT is a sensitive marker with a good negative predictive value for the detection of bacterial infection and is superior to CRP. Low PCT values, particularly when combined with low CRP levels, suggests absence of bacterial infection, alone or in combination with influenza [19-21].

In unvaccinated patients, low anti-H1N1 2009 antibody titers as early as day four after the first influenza symptoms can predict death from fulminant infection. This low level of specific antibodies in the blood does not reflect B-cell deficiencies or an inability to produce antibodies, but reflects instead the trapping of anti-influenza antibodies in immune complexes in the lungs. This suggests that serum antibody to the hemagglutinin (anti-HA) may be used as a marker to predict outcomes in patients infected by IAV [22].

In children, increased monocyte chemotactic protein-3, IFN-a2, and plasma IL-10 levels in nasal samples at enrollment predicted progression to severe disease regardless of viral load and age. This inflammatory cytokine production is correlated significantly with monocyte translocation from the blood to the site of infection [23]. High serum levels of cytokines can coexist with marked innate immune suppression in children with severe influenza. Severe, early innate immune suppression is highly associated with both $S$. aureus coinfection and mortality in this population. Multicenter innate immune function testing is feasible and can potentially better identify these high-risk children.

\section{Immune response modulation, a potential therapeutic in IAV patients}

In infectious diseases, immunomodulation decreases excessive levels of key response factors or molecules, even increases at a low level, and keep the levels adequate in a particular situation. Restoring an immune response that is decreased or enhancing a normal response may increase resistance to infection, reduce its severity, or shorten its recovery period. The role of adjunctive immunosuppressive therapies in pneumonia has been assessed with broad and well-known commercial agents, such as statins or macrolides. Statins have shown anti-inflammatory activity and negative effects on virus replication, an aspect of great interest. $\mathrm{N}$-acetylcysteine has also been shown to be useful in controlling inflammation without increasing viral replication, but there is not enough 
data in the current literature to justify its clinical use. Selective use of cyclooxygenase-2 (COX-2) inhibitors, which include the most commonly used anti-inflammatory drugs, is controversial and this is not recommended. Macrolides have been shown to display in vitro and in vivo beneficial antiinflammatory effects, but these effects have not been reproduced in humans with severe influenza [24]. Adjunctive therapies aimed at modulating increased inflammatory or hypercoagulation states are potential coadjunctive treatments for severe pneumonia.

Recent large and confirmatory randomized controlled trials among patients with bacterial pneumonia suggest that there are subgroups of patients that could theoretically benefit from steroid use [e.g., patients with acute respiratory distress syndrome (ARDS) or relative adrenal insufficiency] and promising new information is still forthcoming. However, in IAV, steroid use seems to stimulate the replication of the virus and, consequently, it has a detrimental effect, increasing superinfections, and its use must be avoided [24-26].

The emergence of resistance to current antiviral drugs increases the need for new therapies. An antiviral used as single dose, a combination of antivirals in pneumonia, and adjunctive immune therapy using antibodies are promising alternatives. Experimental administration of monoclonal antibodies $(\mathrm{mAb})$ showed increased survival, attenuation of histological changes, and a milder inflammatory and oxidative response in the lungs. Newer antivirals and $\mathrm{mAb}$ are currently in various stages of clinical development and, in the near future, may provide useful new tools against the threat of rapid IAV evolution [27].

\section{Conclusion}

Influenza A virus (IAV) infection evolves into severe respiratory failure in some patients, correlated with an exaggerated inflammatory response. At this stage, the mortality rate remains high despite a correct antiviral treatment and additional oxygenation strategies. It is essential to find specific predictive markers for such severity in IAV infection, with the ability to predict a high risk for complications and associated mortality. We need predictors of host response and we need to move measuring lactate to proteomics and transcriptomics. In severe IAV infection, death is a result of pathogenic dysregulation of the immune response. Anti-inflammatory therapies focused on modulating this response to "all patients" have not been satisfactory. Early (single-dose?) antiviral and monoclonal antibodies $(\mathrm{mAb})$ adjunctive therapies represent promising future strategies to improve outcomes in IAV pneumonia. Future research demonstrating the usefulness of adjunctive therapy in a subset of critically ill patients with IAV pneumonia is an unmet clinical need.

\section{Compliance with ethical standards}

Conflict of interest JR has received research grants from Genentech and CIBERES. The other authors do not have any conflicts of interest.

\section{References}

1. Rello J, Pop-Vicas A (2009) Clinical review: primary influenza viral pneumonia. Crit Care 13:R235

2. Rello J, Rodríguez A, Ibañez P, Socias L, Cebrian J, Marques A, Guerrero J, Ruiz-Santana S, Marquez E, Del Nogal-Saez F, Alvarez-Lerma F, Martínez S, Ferrer M, Avellanas M, Granada R, Maraví-Poma E, Albert P, Sierra R, Vidaur L, Ortiz P, Prieto del Portillo I, Galván B, León-Gil C; H1N1 SEMICYUC Working Group (2009) Intensive care adult patients with severe respiratory failure caused by Influenza A (H1N1)v in Spain. Crit Care 13:R148

3. Collins FS, Varmus H (2015) A new initiative on precision medicine. N Engl J Med 372(9):793-795

4. Pérez-Carrasco M, Lagunes L, Antón A, Gattarello S, Laborda C, Pumarola T, Rello J; CRIPS investigators (2015) Influenza infection in the intensive care unit: four years after the 2009 pandemic. Enferm Infecc Microbiol Clin. doi:10.1016/j.eimc.2015.04.004

5. Riera M, Payeras A, Marcos MA, Viasus D, Farinas MC, Segura F, Torre-Cisneros J, Martín-Quirós A, Rodríguez-Baño J, Vila J, Cordero E, Carratalà $\mathrm{J}$ (2010) Clinical presentation and prognosis of the 2009 H1N1 influenza A infection in HIV-1-infected patients: a Spanish multicenter study. AIDS 24:2461-2467

6. Hall MW, Geyer SM, Guo CY, Panoskaltsis-Mortari A, Jouvet P, Ferdinands J, Shay DK, Nateri J, Greathouse K, Sullivan R, Tran T, Keisling S, Randolph AG; Pediatric Acute Lung Injury and Sepsis Investigators (PALISI) Network PICFlu Study Investigators (2013) Innate immune function and mortality in critically ill children with influenza: a multicenter study. Crit Care Med 41(1):224-236

7. Bermejo-Martin JF, Ortiz de Lejarazu R, Pumarola T, Rello J, Almansa R, Ramírez P, Martin-Loeches I, Varillas D, Gallegos MC, Serón C, Micheloud D, Gomez JM, Tenorio-Abreu A, Ramos MJ, Molina ML, Huidobro S, Sanchez E, Gordón M, Fernández V, Del Castillo A, Marcos MA, Villanueva B, López CJ, Rodríguez-Domínguez M, Galan JC, Cantón R, Lietor A, Rojo S, Eiros JM, Hinojosa C, Gonzalez I, Torner N, Banner D, Leon A, Cuesta P, Rowe T, Kelvin DJ (2009) Th1 and Th17 hypercytokinemia as early host response signature in severe pandemic influenza. Crit Care 13(6):R201

8. Díaz E, Rodríguez A, Martin-Loeches I, Lorente L, del mar Martín M, Pozo JC, Montejo JC, Estella A, Arenzana A, Rello J; H1N1 SEMICYUC Working Group (2011) Impact of obesity in patients infected with 2009 influenza A(H1N1). Chest 139:382-386

9. Martin-Loeches I, Lisboa T, Rhodes A, Moreno RP, Silva E, Sprung C, Chiche JD, Barahona D, Villabon M, Balasini C, Pearse RM, Matos R, Rello J; ESICM H1N1 Registry Contributors (2011) Use of early corticosteroid therapy on ICU admission in patients affected by severe pandemic (H1N1)v influenza A infection. Intensive Care Med 37:272-283

10. Tsatsanis C, Margioris AN, Kontoyiannis DP (2010) Association between H1N1 infection severity and obesity-adiponectin as a potential etiologic factor. J Infect Dis 202(3):459-460

11. Burgos J, Larrosa MN, Martinez A, Belmonte J, González-López J, Rello J, Pumarola T, Pahissa A, Falco V (2015) Impact of influenza season and environmental factors on the clinical presentation and outcome of invasive pneumococcal disease. Eur J Clin Microbiol Infect Dis 34:177-186 
12. Robinson KM, Kolls JK, Alcorn J (2015) The immunology of influenza virus-associated bacterial pneumonia. Curr Opin Immunol 34:59-67

13. Rynda-Apple A, Robinson KM, Alcorn J (2015) Influenza and bacterial superinfection: illuminating the immunologic mechanisms of disease. Infect Immun 83:3764-3770

14. Pereira JM, Moreno RP, Matos R, Rhodes A, Martin-Loeches I, Cecconi M, Lisboa T, Rello J; ESICM H1N1 Registry Steering Committee; ESICM H1N1 Registry Contributors (2012) Severity assessment tools in ICU patients with 2009 influenza A (H1N1) pneumonia. Clin Microbiol Infect 18:1040-1048

15. Schuetz P, Hausfater P, Amin D, Amin A, Haubitz S, Faessler L, Kutz A, Conca A, Reutlinger B, Canavaggio P, Sauvin G, Bernard M, Huber A, Mueller B; TRIAGE Study Group (2015) Biomarkers from distinct biological pathways improve early risk stratification in medical emergency patients: the multinational, prospective, observational TRIAGE study. Crit Care 19:377

16. Viasus D, Del Rio-Pertuz G, Simonetti AF, Garcia-Vidal C, AcostaReyes J, Garavito A, Carratalà J (2016) Biomarkers for predicting short-term mortality in community-acquired pneumonia: a systematic review and meta-analysis. J Infect. doi:10.1016/j.jinf.2016.01. 002

17. Valenzuela Sanchez F, Valenzuela Méndez B, Rodríguez Gutierrez JF, Bohollo de Austria R, Rubio Quiñones J, Puget Martínez L, Valiente Alemán I, Estella García A (2015) Initial levels of MRproadrenomedullin: a predictor of severity in patients with influenza a virus pneumonia. Intensive Care Med Exp 3(Suppl 1):A832. doi: 10.1186/2197-425X-3-S1-A832

18. Valenzuela Sanchez F, Valenzuela Méndez B, Rodríguez Gutierrez JF, Bohollo de Austria R, Rubio Quiñones J, Puget Martínez L, Valiente Alemán I, García E (2014) Early ferritin levels, CD56+ percentage and HLA-DR expression acting as prognostic factors in patients with influenza A virus pneumonia. Intensive Care Med 40(Suppl1):S150-S151. doi:10.1007/s00134-013-3451-5, A532

19. Ingram PR, Inglis T, Moxon D, Speers D (2010) Procalcitonin and C-reactive protein in severe $2009 \mathrm{H} 1 \mathrm{~N} 1$ influenza infection. Intensive Care Med 36(3):528-532

20. Cuquemelle E, Soulis F, Villers D, Roche-Campo F, Ara Somohano C, Fartoukh M, Kouatchet A, Mourvillier B, Dellamonica J, Picard
W, Schmidt M, Boulain T, Brun-Buisson C; A/H1N1 REVA-SRLF Study Group (2011) Can procalcitonin help identify associated bacterial infection in patients with severe influenza pneumonia? A multicentre study. Intensive Care Med 37(5):796-800

21. Pfister R, Kochanek M, Leygeber T, Brun-Buisson C, Cuquemelle E, Machado MB, Piacentini E, Hammond NE, Ingram PR, Michels G (2014) Procalcitonin for diagnosis of bacterial pneumonia in critically ill patients during 2009 H1N1 influenza pandemic: a prospective cohort study, systematic review and individual patient data meta-analysis. Crit Care 18(2):R44

22. Guihot A, Luyt CE, Parrot A, Rousset D, Cavaillon JM, Boutolleau D, Fitting C, Pajanirassa P, Mallet A, Fartoukh M, Agut H, Musset L, Zoorob R, Kirilovksy A, Combadière B, van der Werf S, Autran B, Carcelain G; FluBAL Study Group (2014) Low titers of serum antibodies inhibiting hemagglutination predict fatal fulminant influenza A(H1N1) 2009 infection. Am J Respir Crit Care Med 189: 1240-1249

23. Oshansky CM, Gartland AJ, Wong SS, Jeevan T, Wang D, Roddam PL, Caniza MA, Hertz T, Devincenzo JP, Webby RJ, Thomas PG (2014) Mucosal immune responses predict clinical outcomes during influenza infection independently of age and viral load. Am J Respir Crit Care Med 189:449-462

24. Ramos I, Fernandez-Sesma A (2015) Modulating the innate immune response to influenza A virus: potential therapeutic use of anti-inflammatory drugs. Front Immunol 6:361

25. Martin-Loeches I, Lisboa T, Rhodes A, Moreno RP, Silva E, Sprung C, Chiche JD, Barahona D, Villabon M, Balasini C, Pearse RM, Matos R, Rello J; ESICM H1N1 Registry Contributors (2011) Use of early corticosteroid therapy on ICU admission in patients affected by severe pandemic (H1N1)v influenza A infection. Intensive Care Med 37:272-283

26. Zhang Y, Sun W, Svendsen ER, Tang S, MacIntyre RC, Yang P, Zhang D, Wang Q (2015) Do corticosteroids reduce the mortality of influenza A (H1N1) infection? A meta-analysis. Crit Care 19:46

27. Nosaka N, Yashiro M, Yamada M, Fujii Y, Tsukahara H, Liu K, Nishibori M, Matsukawa A, Morishima T (2015) Anti-high mobility group box-1 monoclonal antibody treatment provides protection against influenza A virus (H1N1)-induced pneumonia in mice. Crit Care 19:R249 